\title{
Anabases
}

ANABASES Traditions et réceptions de l'Antiquité

$8 \mid 2008$

Varia

\section{John GRUBER-MILLER (éd.), When Dead Tongues Speak.} Teaching Beginning Greek and Latin

\section{Béatrice Pasa}

\section{(2) OpenEdition}

\section{Journals}

Édition électronique

URL : http://journals.openedition.org/anabases/250

DOI : 10.4000/anabases.250

ISSN : 2256-9421

\section{Éditeur}

E.R.A.S.M.E.

\section{Édition imprimée}

Date de publication : 1 octobre 2008

Pagination : 287-289

ISSN : 1774-4296

\section{Référence électronique}

Béatrice Pasa, « John gruber-mILlen (éd.), When Dead Tongues Speak. Teaching Beginning Greek and Latin », Anabases [En ligne], 8 | 2008, mis en ligne le 01 juillet 2011, consulté le 21 septembre 2020. URL http://journals.openedition.org/anabases/250 ; DOI : https://doi.org/10.4000/anabases.250

Ce document a été généré automatiquement le 21 septembre 2020.

(c) Anabases 


\title{
John GRUBER-MILLER (éd.), When Dead Tongues Speak. Teaching Beginning Greek and Latin
}

\author{
Béatrice Pasa
}

\section{RÉFÉRENCE}

John GRUBER-MILLER (éd.), When Dead Tongues Speak. Teaching Beginning Greek and Latin, Oxford, Oxford University Press, 2006, 238 p.

14,99 livres, ISBN 978-0-19-517495-3

1 Les méthodes d'enseignement du grec et du latin font l'objet de discussions depuis plusieurs années. Ces préoccupations ont conduit, en 1997, à la rédaction du Standards for Classical Language Learning qui jette les bases d'une nouvelle réflexion sur l'enseignement des langues classiques autour de cinq principaux thèmes: la communication, la culture, la connexion, la comparaison et la communauté. C'est dans cette perspective que s'inscrit le livre de J. Gruber-Miller. Cet ouvrage collectif propose de synthétiser les recherches menées depuis une trentaine d'années par les linguistes et psychologues tout en y incluant les travaux et observations des enseignants euxmêmes. Mais plus qu'une bonne synthèse théorique, cet ouvrage présente des implications pédagogiques. En effet, les chapitres sont illustrés par des exemples de situations concrètes accompagnées d'activités collectives et de Travaux dirigés. Cet apport est d'autant plus précieux que les méthodes proposées ont été expérimentées au préalable par les auteurs dans leurs classes, ce qui permet de souligner les forces et les faiblesses de chacune. Ce couple théorie/pratique est complété par une bibliographie sélective et commentée.

2 L'ouvrage est divisé en trois parties. La première, justement intitulé «Setting the Scene ", pose les bases d'un bon apprentissage afin d'adapter l'enseignement du grec et du latin aux changements observés dans les classes ces dernières années. Pour ce faire, 
J. Gruber-Miller (p.9-23) se concentre autour de trois facteurs intrinsèquement liés : la communication (nécessité de redonner vie aux langues en les oralisant), le contexte (importance de replacer les œuvres dans leur contexte culturel et de les relier à notre civilisation) et la communauté (créer un environnement favorable à la communication et l'échange).

3 La seconde partie s'intéresse à l'apprenant («Focus on the Learner »). Elle explore les nombreux facteurs (individuels et collectifs) qui influencent l'apprentissage d'une seconde langue. Après avoir rappelé les principales stratégies cognitives des élèves (A. Deagon, p. 27-49), les auteurs exposent différents moyens d'appréhender les langues classiques. Pour répondre aux difficultés les plus fréquentes (codage linguistique), B. Hill (p.50-67) propose une approche multi sensorielle intégrant des éléments sonores, visuels et kinesthésiques. De même, afin de satisfaire les besoins de l'apprenant en matière de variétés et d'opportunités d'utilisation de la langue, K. Argetsinger (p.68-85) présente deux méthodes : le near-peer teaching et le cooperative learning. La première vise à favoriser l'entraide entre élèves (les élèves plus avancés ou plus expérimentés aident les plus faibles), la seconde tend à organiser des petits groupes de travail réunis autour d'un but commun et à favoriser ainsi l'émulation intellectuelle collective. Enfin, L. J. Churchill (p. 86-109) souligne le rôle des facteurs sociaux et affectifs qui influencent l'apprentissage du latin. Elle révèle les suppositions implicites du genre faites sur la langue latine et la culture romaine dans les manuels et souligne l'impact positif sur les apprenants d'une féminisation de l'enseignement du latin.

4 La dernière partie, " Focus on the language », insiste sur la nécessité de multiplier les usages de la langue à travers quatre moyens principaux : l'écriture, la lecture, la parole et l'écoute et cela dès les débuts de l'enseignement. Après une introduction aux théories de la lecture, les auteurs se concentrent sur les moyens susceptibles de favoriser l'automatisation du décodage. Ainsi, afin de résoudre la difficulté de l'identification des cas, D.V.McCaffrey (p.113-133) encourage le recours aux stratégies utilisées par les Romains eux-mêmes pour pallier les ambiguïtés morphologiques du latin. Dès lors, l'élève peut axer sa lecture sur la sémantique de la phrase et non plus sur le déchiffrement. De plus, K.S. Morrell (p.134-157) rappelle l'importance des connaissances extratextuelles et culturelles pour la compréhension des textes. Pour cela, elle propose un modèle permettant d'intégrer des extraits d'œuvres grecques authentiques dans les cours pour débutants. En outre, la simple pratique du thème ou de la version est présentée comme une utilisation trop restrictive des langues anciennes. Les auteurs soulignent le rôle primordial d'une audience afin de donner un but et un contexte à l'oral, l'écoute, l'écriture et la lecture. P. Saffire (p. 158-189) montre qu'il existe des raisons psychologiques, sociales et cognitives de favoriser les conversations en grec ancien dans les classes en complément des activités de lecture et d'écriture. L'idée de varier les modalités et les situations d'apprentissage est corroborée par J.Gruber-Miller (p. 190-219) qui propose, notamment, de renouer avec les anciennes traditions de la pratique du Logos, de l'Ethos et du Pathos.

Cet ouvrage se présente comme une introduction aux tendances actuelles, prenant en compte les besoins des élèves et le contexte culturel de l'enseignement des langues. En favorisant les approches interactives When Dead Tongues Speak permet de donner une nouvelle voix aux langues mortes au plus grand bénéfice des apprenants. 


\section{AUTEURS}

\section{BÉATRICE PASA}

Université de Toulouse II

beatricepasa@gmail.com 